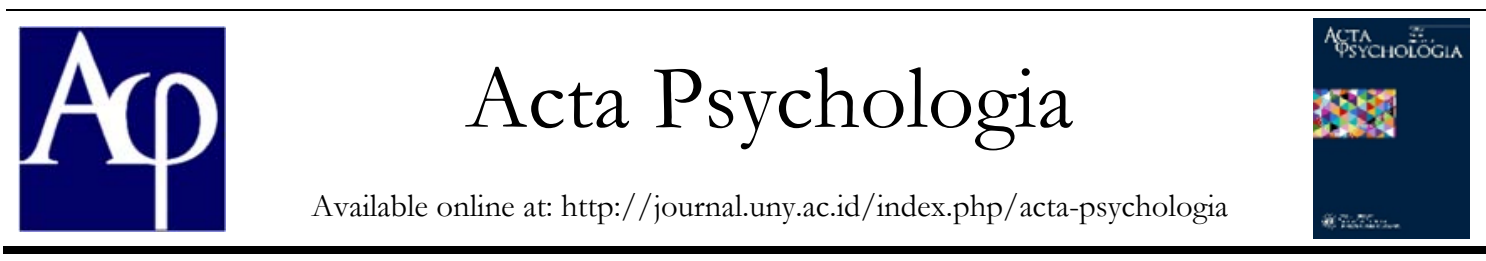

\title{
Hubungan antara Sense Of Humor dengan Kemampuan Interpersonal Karyawan PT. Unicam Indonesia
}

\author{
Dentang Gagat Satria \\ Jurusan Psikologi, Universitas Negeri Yogyakarta; Jl. Colombo No. 1 Sleman Yogyakarta, 55281 \\ dgagats@gmail.com
}

\begin{abstract}
Abstrak
Berdasarkan hasil survei yang dilakukan peneliti, ditemukan bahwa sense of humor mampu membantu individu memiliki kemampuan interpersonal yang baik sehingga individu mampu menjalin hubungan yang baik dengan individu lain. Oleh karena itu, penelitian ini bertujuan untuk mengetahui hubungan antara sense of bumor dengan kemampuan interpersonal pada karyawan PT. Unicam Indonesia. Penelitian ini menggunakan pendekatan kuantitatif dan termasuk penelitian ex-post facto. Subjek penelitian ini adalah seluruh karyawan berjumlah 22 orang di PT. Unicam Indonesia. Instrumen penelitian yang digunakan adalah skala kemampuan interpersonal dan skala sense of humor. Hasil penelitian ini menunjukkan kemampuan interpersonal berada pada kategori sedang dan sense of bumor cenderung berada pada kategori tinggi dan sangat tinggi. Hasil uji korelasi menunjukkan koefisien korelasi sebesar 0,306 yang berarti hubungan antar variabel masuk dalam kategori cukup. Oleh karena itu, dapat disimpulkan bahwa terdapat hubungan antara sense of humor dengan kemampuan interpersonal.
\end{abstract}

Kata Kunci: sense of humor, kemampuan interpersonal

\begin{abstract}
Based on the survey result that was conducted by researcher, it was found that a sense of humor is able to help individuals have a good interpersonal skills so that individuals are able to establish a good relationship with other individuals. Therefore, this study aims to determine the correlation between sense of humor and interpersonal skills on PT. Unicam Indonesia's employees. This is a quantitative research that was included in ex-post facto research. The subjects involved in this study were all of 22 employees of PT. Unicam Indonesia. The research instrument used in this research was a scale of interpersonal abilities and a scale of sense of humor. Based on descriptive analysis, interpersonal skills are at medium category and the sense of humor are at high and very high categories. Correlation test results showed a correlation coefficient of 0.306 , which means the correlation between variables included in the medium category. Therefore, it can be concluded that sense of humor and interpersonal skills have a correlation.
\end{abstract}

Keywords: sense of humor, interpersonal skills

\section{Pendahuluan}

Perkembangan industri manufaktur di Indonesia dapat dikatakan bagus. Menteri Perindustrian Republik Indonesia, Airlangga Hartanto, menyatakan bahwa industri manufaktur di Indonesia dinilai semakin produktif dan kompetitif (Surya, 2019). Hal tersebut dapat dilihat dari data yang dirilis oleh Badan Pusat Statistik (BPS) yang menunjukkan bahwa produksi industri manufaktur besar dan sedang
(IBS) mengalami kenaikan dari tahun sebelumnya menjadi 4,45\% pada kuartal 1 tahun 2019. Angka tersebut lebih tinggi dibandingkan perolehan tahun sebelumnya yaitu 4,07\%. Dampak juga dirasakan oleh masyarakat dengan penyerapan tenaga kerja sebanyak 18, 25 juta sepanjang tahun 2018.

Data BPS menunjukkan bahwa Indonesia saat ini juga telah menjadi negara dengan basis industri manufaktur terbesar 
se-ASEAN. Kontribusi Indonesia mencapai $20,27 \%$ pada perekonomian skala nasional. Dilihat dari nilai MVA atau Manufacturing Value Added, Indonesia menempati peringkat teratas di ASEAN dengan pencapaian sebesar 4,5\%. Hal tersebut sekaligus menjadikan Indonesia menduduki peringkat ke-9 dunia.

Dengan pencapaian tersebut, tentu ada beban yang diemban oleh perusahaan manufaktur. Tuntutan untuk mempertahankan angka-angka yang telah dicapai atau bahkan meningkatkannya untuk kemajuan perusahaan itu sendiri maupun kemajuan perekonomian di Indonesia. Demi menjaga agar mampu tetap kompetitif, kebutuhan akan kondisi internal yang baik dalam perusahaan tentunya menjadi hal mutlak yang harus diperhatikan. Kondisi internal perusahaan merupakan modal utama yang menentukan kuat lemahnya sebuah perusahaan dalam persaingan industri.

Salah satu hal yang mampu membangun kekuatan internal dalam sebuah perusahaan adalah kemampuan interpersonal karyawan. Asrifah (2015) mengemukakan bahwa kemampuan membina hubungan interpersonal yang baik dengan karyawan lain, akan menciptakan lingkungan kerja yang nyaman. Dengan terciptanya lingkungan kerja yang nyaman, hal tersebut akan meningkatkan motivasi kerja bagi karyawan dan memacu karyawan untuk meningkatkan kinerjanya agar menjadi lebih baik.

Menurut Hakim (2014) hubungan interpersonal adalah hubungan yang menunjukkan ketika kita berkomunikasi, kita tidak hanya sekadar menyampaikan informasi, tetapi secara tidak sadar kita juga menentukan kadar hubungan emosional dengan lawan bicara kita. Kemampuan dalam berkomunikasi dan berhubungan interpersonal disebut kemampuan interpersonal. Lebih detail Anderson (1999) mengungkapkan kemampuan interpersonal merupakan kemampuan dan keterampilan seseorang dalam menciptakan relasi, membangun relasi dan mempertahankan relasi sosialnya sehingga kedua belah pihak berada dalam situasi yang menguntungkan.

Berdasarkan pernyataan di atas, kemampuan interpersonal diketahui memiliki andil besar dalam mendukung kelancaran komunikasi dalam sebuah organisasi. Sistem komunikasi yang baik akan meminimalisir kesenjangan, rasa saling tidak percaya, kecurigaan serta menimbulkan kenyamanan dalam lingkungan kerja yang nantinya akan mendukung kinerja yang maksimal dari karyawannya. Salah satu hal yang dinilai mampu membantu untuk meningkatkan kualitas hubungan interpersonal individu adalah dengan membangun kegembiraan di tempat kerja menggunakan humor. McGee dan Shevlin (2009) melakukan penelitian mengenai keinginan bersosialisasi. Hasil penelitian tersebut menyatakan bahwa sense of bumor termasuk dalam karakteristik kepribadian yang dinilai paling menguntungkan dalam kehidupan interpersonal individu. Dengan adanya social cohesion dan penerimaan diri yang baik, karyawan diharapkan memiliki kemampuan interpersonalnya yang baik tidak terkecuali dalam lingkungan sosial dimana individu bekerja.

Menurut Hartanti (2008) humor merupakan sifat dari sesuatu atau situasi yang kompleks yang menimbulkan keinginan untuk tertawa. Hughes (2008) menjelaskan sense of bumor merupakan kemampuan setiap orang dalam mempersepsikan, mengekspresikan dan menikmati humor.

Martin (2007) mengatakan bahwa menggunakan humor dalam melakukan komunikasi interpersonal dapat mengurangi risiko terjadinya permusuhan atau rasa dendam antara pihak pemberi informasi maupun penerima informasi karena humor mengindikasikan adanya penerimaan sosial terhadap diri individu. Dengan adanya penerimaan sosial yang 
baik, individu tersebut merasa dekat satu sama lain (social cohesion). Pendekatan yang lebih dalam dari sekadar percakapan diharapkan akan mampu meningkatkan hubungan antar pribadi menjadi baik, menciptakan suasana komunikasi yang baik pula sehingga mereduksi ketegangan yang terjadi antar individu yang ditakutkan menjadikan hubungan keduanya buruk seperti timbul kecurigaan, permusuhan bahkan dendam.

Berdasarkan beberapa penelitian yang pernah dilakukan sebelumnya menunjukkan bahwa sense of humor sering kali dikaitkan dengan kemampuan interpersonal individu. Oleh karena itu, peneliti tertarik untuk meneliti tentang adanya hubungan antara sense of bumor dengan kemampuan interpersonal pada karyawan industri manufaktur. Idealnya perusahaan mengharapkan adanya hubungan interpersonal yang baik untuk mendukung karyawannya menghasilkan kinerja dan produktivitas yang baik dalam perusahaan, namun pada kenyataannya hubungan interpersonal yang kurang baik memberi dampak kinerja dan produktivitas karyawan. Penelitian ini penting dilakukan untuk mengetahui dan memahami bagaimana hubungan sense of bumor dengan kemampuan interpersonal pada karyawan.

\section{Metode Penelitian}

Penelitian ini merupakan penelitian kuantitatif yang meneliti keseluruhan atau populasi dalam suatu perusahaan. Penelitian ini juga menggunakan metode ex-post facto yang bertujuan meneliti hubungan sebab-akibat yang tidak dimanipulasi.

Penelitian ini dilakukan di PT. Unicam Indonesia Dhuri, Tirtomartani, Kalasan, Sleman, Yogyakarta pada Oktober 2019 hingga November 2019.

Subjek penelitian ini adalah seluruh karyawan PT. Unicam Indonesia yang berjumlah 22 orang.
Teknik pengumpulan data pada penelitian ini menggunakan skala kemampuan interpersonal yang disusun berdasarkan teori Anderson (1999) yang terdiri dari dimensi social sensitivity, social insight, dan social communication. Sedangkan skala sense of bumor disusun berdasarkan teori milik Thorson dan Powell (1997) yang terdiri dari aspek bumor production, coping with bumor, bumor appreciation, dan attitude toward bumor. Terdapat empat pilihan jawaban yaitu sangat tidak sesuai, tidak sesuai, sesuai, dan sangat sesuai.

Penelitian ini menggunakan validitas isi berupa expert judgement yang lalu diujikan kepada subjek penelitian setelah dinyatakan valid. Setelah itu dilakukan pula uji validitas menggunakan Pearson Product Moment untuk menyeleksi aitem.

Selain uji validitas, uji reliabilitas juga dilakukan dalam penelitian ini menggunakan rumus Cronbach Alpha melalui program SPSS 25. Dari uji reliabilitas tersebut didapatkan hasil 0,704 untuk skala kemampuan interpersonal dan 0,863 untuk skala sense of humor.

Teknik analisis data dalam penelitian ini menggunakan analisis deskriptif dan uji hipotesis menggunakan uji korelasi Kendall's tahu-b.

\section{Hasil Penelitian}

Hasil analisis deskriptif karakteristik subjek menunjukkan bahwa kebanyakan berusia 20-30 tahun. Jumlah laki-laki dan perempuan cukup berimbang yaitu 12 lakilaki dan 10 perempuan. Karyawan dalam perusahaan ini mayoritas memiliki pendidikan SMA/SMK. Lama kerja karyawan rata-rata 1 hingga 2 tahun.

Hasil analisis deskriptif menunjukkan bahwa kebanyakan karyawan memiliki tingkat kemampuan interpersonal sedang dengan persentase sebesar $50 \%$ dari total responden atau sebanyak 11 karyawan. Adapun sebaran datanya adalah sebagai berikut: 


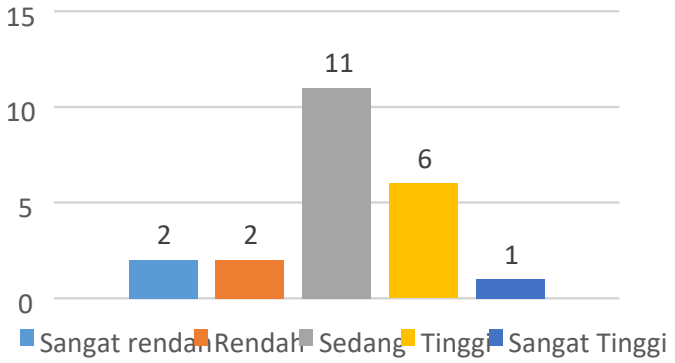
Gambar 1. Sebaran Data Kategorisasi Kemampuan Interpersonal

Analisis deskriptif pada Variabel sense of humor menunjukkan bahwa kebanyakan karyawan memiliki tingkat sense of bumor tinggi dan sangat tinggi dengan persentase $40,9 \%$ atau sebanyak 9 karyawan pada masing-masing kategori. Adapaun sebaran datanya adalah sebagai berikut:

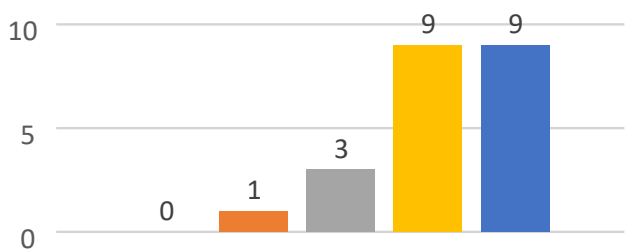

Sangat Rendan Rendah Sedang Tinggi Sangat Tinggi Gambar 2. Sebaran Data Kategorisasi Sense of Humor

Uji korelasi Kendall's tahu-b menunjukkan bahwa nilai koefisien korelasi sebesar 0,306 yang termasuk dalam kategori cukup atau sedang. Berdasarkan hasil tersebut dapat disimpulkan bahwa terdapat hubungan antara kemampuan interpersonal dengan sense of bumor.

\section{Pembahasan}

Berdasarkan analisis deskriptif, diperoleh hasil yaitu rata-rata kemampuan interpersonal karyawan berada pada tingkat sedang dengan persentase sebanyak 50\% dari total responden atau berjumlah 11 karyawan. Hidjaz (2011) menyatakan bahwa perilaku interpersonal berkaitan dengan beberapa aspek lingkungan fisik seperti ruang personal, teritorialitas, kesesakan, kepadatan dan privasi. PT. Unicam Indonesia mengusung tata ruang kerja berupa ruanganruangan bersekat yang memisahkan antar ruang pribadi karyawan.

Dengan desain seperti itu, karyawan membutuhkan usaha lebih untuk berinteraksi dengan karyawan lain sehingga ada pilihan untuk tidak melakukan interaksi jika tidak terlalu membutuhkan. Dengan demikian kemampuan interpersonal karyawan kurang terasah dengan baik. Namun interaksi antar karyawan sering dilakukan ketika istirahat makan siang dan di luar jam kerja lewat media sosial seperti grup Whatsapp, Instagram, dll.

Berdasarkan hasil analisis deskriptif, variabel sense of humor berada pada tingkat tinggi dan sangat tinggi dengan jumlah responden yang sama yaitu 9 pada masingmasing kategori. Humor bisa didapatkan di mana saja, beberapa diantaranya media sosial. Subjek dalam penelitian ini sebagian besar berusia 20-30 tahun yaitu berjumlah 14 orang atau sebesar 63,6\%. Ditambah lagi peringkat kedua terbanyak merupakan subjek yang berusia di bawah 20 tahun yaitu berjumlah 3 orang atau sebesar $14,6 \%$.

Individu dengan rentang usia tersebut merupakan individu yang sangat dekat dengan penggunaan media sosial hampir dalam setiap kegiatan sehari-hari. Hal tersebut menjadikan media sosial merupakan media yang efektif dalam membentuk sense of bumor individu dikarenakan banyak konten lucu yang tersebar di media sosial seperti instagram, twitter, facebook, youtube, dll. Hal yang individu dapat dari media sosial tersebut biasanya lalu dibawa ke tempat kerja untuk dibicarakan bersama atau sekadar ditertawakan bersama.

Hasil uji hipotesis, menggunakan uji korelasi Kendall's tau-b, diperoleh nilai koefisien korelasi antara variabel sense of bumor dan kemampuan interpersonal sebesar 0,306. Nilai tersebut termasuk dalam kategori cukup atau sedang. Maka dari itu, dapat disimpulkan bahwa terdapat hubungan positif antara sense of bumor dengan kemampuan interpersonal. 
Sense of bumor dalam beberapa penelitian dikemukakan sebagai hal yang mampu memberi dampak positif dalam komunikasi. Penelitian yang dilakukan oleh Romero dan Cruthirds (2006) menyatakan bahwa penggunaan humor dalam suatu organisasi mampu meningkatkan komunikasi antar pribadi dalam organisasi tersebut. Andrew (2010) menambahkan bahwa humor mampu bertindak sebagai pengaruh yang kuat dalam mencairkan suasana yang tegang dan membangun interaksi dengan orang lain dalam komunikasi interpersonal.

Dalam kasus di PT. Unicam Indonesia, sense of humor, yang cenderung tinggi dan sangat tinggi, dimanfaatkan karyawan sebagai sarana berkomunikasi. Pemanfaatan sense of humor, yang termasuk dalam kategori tinggi dan sangat tinggi, tersebut diterapkan dengan baik untuk meningkatkan kemampuan interpersonal karyawan sehingga mampu membuat komunikasi menjadi efektif. Dampak dari desain ruang bersekat menjadi tidak terlalu dirasakan dan tidak membuat kemampuan interpersonal karyawan rendah, menjadi bukti pemanfaatan sense of humor dalam meningkatkan kemampuan interpersonal karyawan.

Menurut Hartanti (2002) sense of humor seseorang dipengaruhi oleh beberapa hal seperti pengetahuan, latar belakang sosial budaya, sehingga tidak tergantung pada stimulus luar. Karyawan PT. Unicam Indonesia mayoritas atau sebesar 77,3\% sudah bekerja lebih dari 1 tahun yang artinya sudah lebih dari 1 tahun mereka bekerja bersama-sama. Dalam rentang waktu tersebut dapat membentuk suatu lingkungan sosial atau lingkaran pertemanan baru. Ditambah lagi 63,6\% karyawan memiliki rentang usia 20-30 tahun. Hal tersebut membuat individu dapat memiliki referensi humor yang relatif sama. Oleh karena itu akan lebih mudah untuk memiliki kemampuan dalam menjalin hubungan interpersonal dengan memanfaatkan referensi humor yang relatif sama.

\section{Simpulan dan Saran}

Berdasarkan hasil analisis data dan pembahasan, maka hasil penelitian dapat disimpulkan sebagai berikut: 1) Kemampuan interpersonal karyawan PT. Unicam Indonesia sebagian besar berada pada kategori sedang. 2) Sense of bumor karyawan PT. Unicam Indonesia sebagian besar berada pada kategori tinggi dan sangat tinggi.3) Terdapat hubungan antara sense of bumor dengan kemampuan interpersonal pada karyawan PT. Unicam Indonesia.

Saran dari hasil penelitian ini adalah: 1) Bagi perusahaan diharapkan beberapa kegiatan bisa dijadikan alternatif untuk dilakukan perusahaan seperti mengadakan kegiatan bersama yaitu gathering atau outbond. Hal yang perlu diperhatikan untuk memaksimalkan potensi sense of bumor karyawan agar mampu membangun kemampuan interpersonal adalah membuat kegiatan tersebut memiliki suasana humoris dengan menyisipkan humor-humor ringan. 2) Bagi karyawan diharapkan sense of humor yang tinggi bisa menjadi modal yang mampu digunakan untuk meningkatkan kemampuan interpersonal. Salah satu caranya bisa dilakukan dengan menyisipkan humor dalam percakapan seharihari dengan karyawan lain. 3) Bagi penelitian selanjutnya disarankan untuk memilih alternatif lain untuk variabel bebas yang bisa dikaitkan dengan kemampuan interpersonal agar bisa melihat pengruh dan hubungan yang lain. Peneliti juga disarankan agar mengambil jumlah subjek yang lebih banyak sehingga akan meningkatkan akurasi, reliabilitas dan validitas. Referensi dan teori yang digunakan pun bisa ditambah agar semakin kaya untuk menggambarkan hasil. 


\section{Daftar Pustaka}

Anderson. (1999). The Development of Intelligence. Psychological Press: United Kingdom.

Andrew, R. (2010). Inercultural Commnication and The Essence of Humour. Journal of Communication. Vol. 29, No. 1: 23-24.

Asrifah. (2015). Pengaruh Human Relations terhadap Kinerja Pegawai di Kantor Wilayah Kementerian Agama Provinsi Sulawesi Tengah. Ejournal Katalogis. Vol. 3, No. 2:125134.

Hakim, Y. (2014). Pengaruh Hubungan Interpersonal dan Lingkungan Kerja terhadap Kepuasan Kerja Perawat di Ruangan UGD RSUD Salewangang Maros. Jurnal Ilmiah Kesehatan Diagnosisi. Vol. 4, No. 5:541-548.

Martin. (2007). The Psychology of Humor Integrative Approach. Kanada: Elsevier Academic Press.

McGee \& Shevlin. (2009). Psychology of Humor : A Reference Guide and Annotated Bibliography. United States: Greenwood Press.

Surya, E. (2019). Kuartal I-2019 Produksi Industri Manufaktur Besar dan Sedang Naik $\quad 4,45 \%$, https://setkab.go.id/kwartal-i2019produksi-industri-manufakturbesardan-sedang-naik-445-persen/, diakses pada 18 Agustus 2019 pukul 22.10 .

Romero, E. J., \& Cruthirds, K. W. (2006). The Use of Humor in The Workplace. Journal of Human Relation. Vol. 61, No. 3:256-277.

Hartanti. (2002). Peran Sense of Humor dan Dukungan Sosial pada Tingkat
Depresi pada Penderita Dewasa Pasca Stroke. Anima, Indonesian Psychological Journal. Vol. 17, No. 2: 107-119.

- (2008). Apakah Selera Humor Menurunkan Stres? Sebuah Metaanalisis. Anima, Indonesian Psychological Journal. Vol. 24, No. 1:38-55.

Hughes, L. W. (2008). A Correlational Study of the Relationship between Sense of Humor and Positive Pychological Capacities. Economic and Business Journal: Inquiries and Perspectives. Vol. 1, No. 1:46-55.

Thorson, J. A. \& Powell, F. C. (1997). Psychological Health and Sense of Humor. Journal of Clinical Psychology. Vol. 53, No. 6: 605-619. 